\title{
Morphological Characterization of Pollen from some Species of the Genus Echeveria. From Mexican Territory.
}

González-Mancera G. ${ }^{1}$, Reyes-Santiago J. ${ }^{2}$, Luna-Islas M.A. ${ }^{2}$, Sanchez-Sixtos N. A.

${ }^{1}$ Universidad Nacional Autónoma de México, Facultad de Química. Departamento de Ing. Metalurgica, Ciudad Universitaria, 04510 México, D. F. México.Email: ggm@unam.mx

${ }^{2}$ Universidad Nacional Autónoma de México, Jardín Botánico, Ciudad Universitaria, 04510 México, D. F. México. Email: jreyes@ibiologia.unam.mx

Echeveria is a large genus of America Crassulaceae, extending from Texas to Argentina. And Mexico have the most endemism and diversity of this group of plants [1], eighty-five percent of its species are located in Mexico. Genus of Echeveria is considered by horticulturists and collectors as ornamental plants highly appreciated. Many of their species are extracted from their natural habitat in order to attend national and international demands [2]. Unfortunately many are at risk of extinction and most are poorly documented.

This work presents, to our knowledge, the first results from palinogycal characteristics of some species from Echeveria by SEM. The purpose of this study is to contribute, through its morphologycal analysis to the identification of its species. The pollen was obtained from ten species (E. affinis, E. gracilis, E. heterosepala, E. hyalina, E. juliana, E. nebularum, E. rosaiflores, E. setosa var. Ciliata, E. setosa var setosa, E. simulans) from the Botanical Garden collection in UNAM. Grains were mounted in holders and cover with graphite and gold, and analyzed by SEM. Studied pollen presents the following taxonomical characteristics [Table 1]: sizes between $19 \mu \mathrm{m}$ and 30 $\mu \mathrm{m}$, subespheroidal shape [Figure 1a] except by E. gracilis and E. nebularum that have oblate [Figure 1b], three apertures most of tipe colpi [Figure 1a-b], except in E. affinis, E. rosaiflores and E. simulans, where pore and colpus are combined [Figure 1c] in the aperture. Sculpture of their exine are essentially reticulate [Figure 1d], only two species present striate [Table 1, Figure 1e]. It is observed that pollen studied here is mainly subespheroidal and presents smaller sizes than grains (in previous study) [3] that presented prolate shape and sizes from $36 \mu \mathrm{m}$ to $47 \mu \mathrm{m}$. These results suggests that most of the studied species of Echeveria present similar characteristics, but there is some exceptions that show different features, for example, grains with colporate or fenestrate condition. 
Table 1. Analyzed pollen characteristics from some species of Echeveria sp.

\begin{tabular}{|l|c|c|l|c|}
\hline SPECIE Echeveria & $\begin{array}{c}\text { SIZE } \\
(\boldsymbol{\mu m})\end{array}$ & SHAPE & $\begin{array}{c}\text { APERTUR } \\
\mathbf{E}\end{array}$ & $\begin{array}{c}\text { ORNAMENTATIO } \\
\mathbf{N}\end{array}$ \\
\hline E. affinis & 19.4 & subspheroidal & tricolporate & striate \\
\hline E. gracilis & 23.7 & oblate & tricolpate & reticulate \\
\hline E. heterosepala & 27.5 & subspheroidal & tricolpate & reticulate \\
\hline E. hyalina & 29.9 & subspheroidal & tricolpate & reticulate \\
\hline E. juliana & 26.8 & subspheroidal & tricolpate & striate \\
\hline E. nebularum & 29.3 & oblate & tricolpate & reticulate \\
\hline E. rosaiflores & 30,8 & subspheroidal & tricolporate & reticulate \\
\hline E. setosa var. ciliata & 20.4 & subspheroidal & tricolpate & reticulate \\
\hline E. setosa var setosa & 24.4 & subspheroidal & tricolpate & reticulate fenestrate \\
\hline E. simulans & 26.1 & subspheroidal & tricolporate & reticulate - fenestrate \\
\hline
\end{tabular}
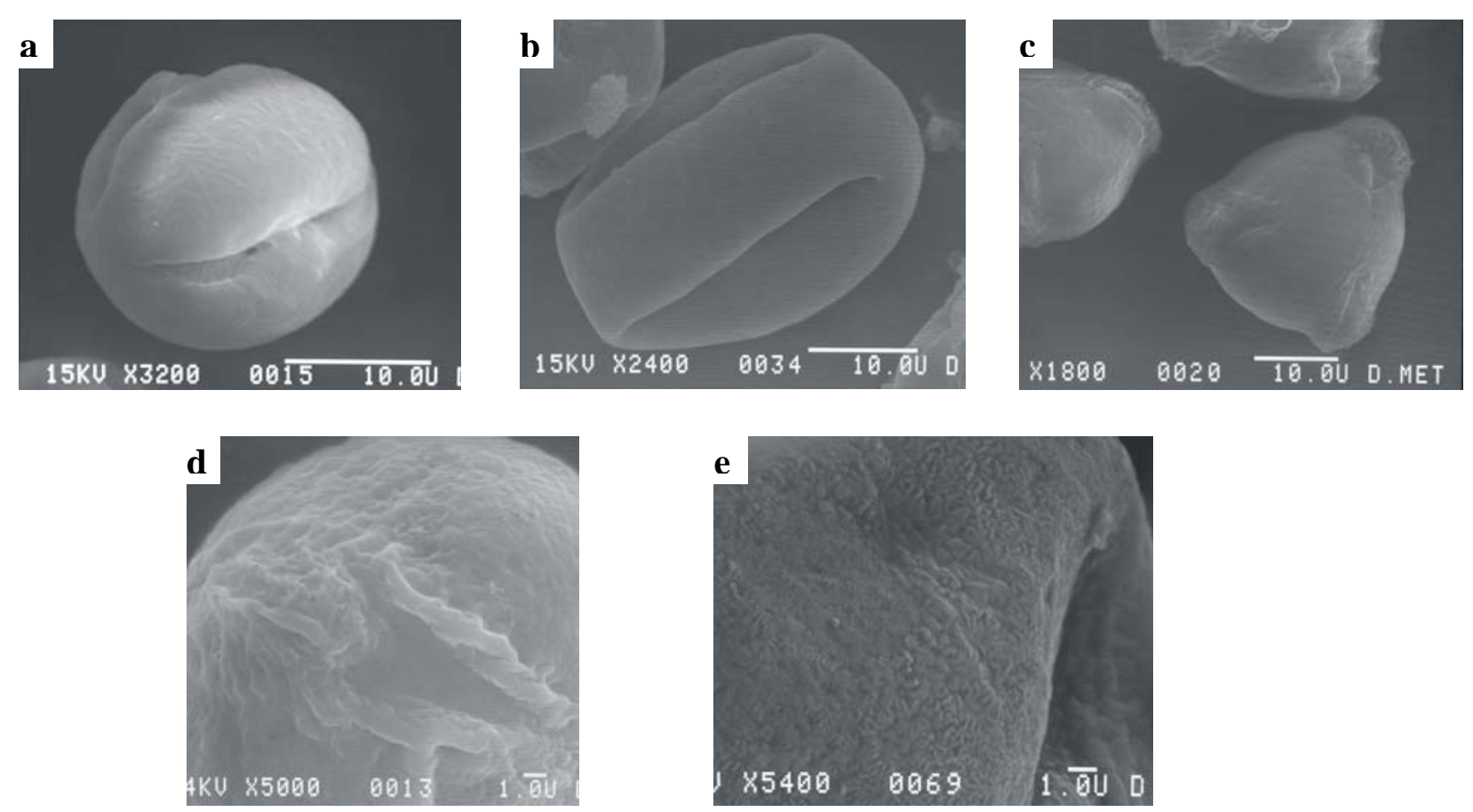

Figure 1a-e. SEM representative images from Echeveria studied pollen. a. E. affinis shows spheroidal shape, b. E. nebularum presents oblate aspect, c. E. simulans in equatorial plane shows its colporate aperture, d. E. simulans exhibit reticulate and fenestrate appearance, e. E. juliana with striate ornamentation.

\section{References:}

[1] Meyran, J., L. López, "Las Crassulaceas de México”, Sociedad Mexicana de cactología, A.C., México, (2003), 286 p.

[2] Reyes S. J. et al., "Manual del perfil diagnostico del género Echeveria en México”, SINAREFI, (2011), $131 \mathrm{p}$. 